Tohoku J. Exp. Med., 2007, 213, 269-276

\title{
Association between Low Serum Ferritin and Restless Legs Syndrome in Patients with Attention Deficit Hyperactivity Disorder
}

\author{
Pinar Oner, ${ }^{1}$ Ebru Bilge Dirik, ${ }^{2}$ Yasemen Taner, ${ }^{3}$ Ali Caykoylu ${ }^{4}$ and Omer Anlar ${ }^{2}$ \\ ${ }^{1}$ Child and Adolescent Psychiatry Division, Ataturk Hospital, Ankara, Turkey \\ ${ }^{2}$ Neurology Department, Ataturk Hospital, Ankara, Turkey \\ ${ }^{3}$ Child and Adolescent Psychiatry Department, Ufuk University Medical School, Ankara, Turkey \\ ${ }^{4}$ Psychiatry Department, Ataturk Hospital, Ankara, Turkey
}

Oner, P., Dirik, E.B., Taner, Y., Caykoylu, A. and Anlar, O. Association between Low Serum Ferritin and Restless Legs Syndrome in Patients with Attention Deficit Hyperactivity Disorder. Tohoku J. Exp. Med., 2007, 213 (3), 269-276 — Attention deficit hyperactivity disorder (ADHD) is a neurobehavioral disorder characterized by pervasive inattention and/or hyperactivity-impulsivity. It has been suggested that ADHD symptoms are associated with restless legs syndrome (RLS), which is a neurological condition that is defined by an irresistible urge to move the legs. Increasing evidence suggests iron deficiency may underlie common pathophysiological mechanisms in subjects with ADHD and with RLS. To further define the relationship between iron deficiency and RLS in children and adolescents with ADHD, we evaluated 87 ADHD subjects: 79 boys and 8 girls with age $9.3 \pm 2.5$ years (6-16 years). Various psychopathologies and the severity of the ADHD symptoms and serum ferritin levels were assessed. Diagnosis of RLS was made according to the International RLS Group criteria. The patients were evaluated for the iron deficiency (ferritin $<12 \mathrm{ng} / \mathrm{ml}$ ). RLS was found in $29(33.3 \%)$ of the 87 ADHD subjects. Parentand teacher-rated behavioral and emotional problems and the severity of ADHD symptoms were not significantly different between ADHD subjects with RLS and those without RLS $(n=58)$. The rate of iron deficiency was significantly higher in ADHD subjects with RLS $(n=6,20.7 \%)$ when compared with ADHD subjects without RLS $(n=1,1.7 \%, p=0.005)$. Our results showed that depleted iron stores might increase the risk of having RLS in ADHD subjects. Iron deficiency, which is associated with both ADHD and RLS, seems to be an important modifying factor in the relationship between these two conditions. — restless legs syndrome; attention deficit hyperactivity disorder; iron deficiency; ferritin; dopamine

(C) 2007 Tohoku University Medical Press

Attention deficit hyperactivity disorder (ADHD) is one of the most common neuropsychiatric disorders of childhood. ADHD consists of two symptom domains, namely hyperactivity/ impulsivity and inattentiveness (American Psychiatric Association 1994). It has been suggested that ADHD are associated with restless legs syndrome (RLS) (Cortese et al. 2005). RLS

Received July 10, 2007; revision accepted for publication October 3, 2007.

Correspondence: Dr. Pinar Oner, Child and Adolescent Psychiatry Division; Sami Ulus Children's Hospital Babur Cad. No: 44 pk: 06080 Altindag, Ankara, Turkey.

e-mail: pinaryoner@yahoo.com 
is a common condition with a prevalence of almost 11\% (Berger et al. 2004; Hogl et al. 2005). There are two types of RLS: idiopathic and symptomatic (secondary). Several studies demonstrated that $50 \%$ of restless legs syndrome (RLS) patients have a positive family history and it has been suggested that RLS is a highly hereditary trait. Linkage analysis uncovered five loci based on recessive (RLS1) or dominant inheritance (RLS2-RLS5) (Winkelmann et al. 2007a), a recent genome-wide reported significant associations between RLS and three genes (Winkelmann et al. 2007b). Another group has discovered a variant associated with susceptibility to periodic limb movements in sleep, which was also inversely correlated with iron stores (Stefansson et al. 2007). Symptomatic RLS is related to pregnancy, uremia, iron deficiency, polyneuropathy and rheumatoid arthritis, with iron deficiency being the most common cause (Rijsman and Weerd 1999; Polydefkis et al. 2000; Allen 2004; Manconi et al. 2004).

Both ADHD and RLS may be associated with alterations in the dopaminergic system. Animal, lesion, neuroimaging and genetics studies have indicated that dopamine is a key element of ADHD pathophysiology (Oades et al. 1986; Nieoullon 2002). Some authors suggested that the lack of efficient dopaminergic control in the cortical and limbic striatal areas might result in selective attention and behavioral inhibition (Russel et al. 1995; Sagvolden 2000). RLS pathophysiology is also closely related to dopaminergic system; the first choice of treatment is dopaminergic agents (Trenkwalder et al. 2005), while the dopamine antagonists exacerbate the symptoms (Winkelman et al. 2006). Some imaging studies have shown that patients with RLS had abnormal dopamine receptor bindings or transport (Winkelman et al. 2006).

Another common feature of ADHD and RLS is association with iron deficiency. Studies investigating the relationship between ADHD and iron metabolism showed that children with ADHD had lower mean ferritin levels when compared with normal controls and that low serum ferritin levels were related to more severe symptoms as indicat- ed by higher Conners Parent Rating Scale scores (Konofal et al. 2004). Other studies have focused on the utility of iron supplementation in ADHD, with conflicting results (Sever et al. 1997). Serum ferritin level is related to RLS severity (Krieger and Schroeder 2001), and since most of the subjects with iron deficiency do not have anemia, low serum or cerebro-spinal fluid ferritin levels may be the only significant parameter (Sun et al. 1998; Kryger et al. 2002; Mizuno et al. 2005). Thus, it has been recommended that serum ferritin level must be evaluated in every RLS subject (Trenkwalder et al. 2005). It has been reported that decreased brain iron concentration might be due to dysfunctional transportation of iron from serum to the cerebrospinal fluid (Mizuno et al. 2005). It has been shown that the transport of iron into dopaminergic cells might be decreased in RLS (Connor et al. 2003). Iron is a coenzyme of tyrosine hydroxylase, which is critical in dopamine synthesis (Wigglesworth and Baum 1988). Iron is also related to monoamine oxidase, which is critically related to the degradation of dopamine. Iron is colocalized with dopaminergic neurons in the brain (Wigglesworth and Baum 1988) and D2 and D4 receptor and dopamine transporter densities decrease with decreased brain iron levels (Askhenazi et al. 1982; Ericson et al. 1997). Therefore, the relationship between iron deficiency, ADHD and RLS may be linked to alterations in the dopaminergic system.

Overall, the studies mentioned above suggest that iron deficiency, RLS and ADHD might be interrelated, perhaps via alterations in the dopaminergic system. In fact, previous studies have shown that all of these conditions might co-occur frequently (Cortese et al. 2005). In this study, our aim was to investigate the relationship among iron stores (indicated by serum ferritin), iron deficiency and RLS in children and adolescents with ADHD.

\section{METHODS}

\section{Population and sampling}

Sample included 87 ADHD subjects (79 boys, 8 girls; age 6-16; mean \pm S.D. $=9.3 \pm 2.5$ ). All subjects were recruited from the general outpatient clinic of a 
general hospital that fulfilled the inclusion criteria. Informed consent process was verbal as is customary given the literacy level of the parents. The parents could select to opt out of the study but none of the parents refused to participate.

Parents and children were interviewed about children's medical history; all ADHD subjects had unremarkable medical history and were clinically screened for psychosis, eating disorders, substance use disorders, pervasive developmental disorders, and mental retardation. All subjects were clinically evaluated for primary (due to conditions inherent to the mechanisms by which sleep is regulated, e.g.parasomnias [Mendelson 2005]) and secondary sleep disorders due to conditions such as allergy and asthma. No patient with an identified sleep disorder was determined.

All patients were diagnosed for the first time and had never been evaluated for psychiatric disorders or treated with psychopharmacological medicine. Inclusion criteria included ADHD diagnosis per Kiddie-SADSLifetime Version (KSADS-PL, [Kaufman et al. 1997]) semi-structured interview, and being between 5-16 years of age. Exclusion criteria included presence of primary or secondary sleep disorders, epilepsy, peripheral neuropathy, radiculopathy, psychosis, mental retardation and any acute medical condition that might lead to alterations in serum ferritin and iron levels.

\section{Behavioral measures}

Kiddie-SADS-Lifetime Version (KSADS-PL). This is a semi-structured diagnostic interview designed to assess current and past episodes of psychopathology in children and adolescents according to DSM-III-R and DSM-IV criteria (Kaufman et al. 1997). Its reliability and validity test for Turkish was carried out (Gokler et al. 2004). Diagnosis was based on DSM-IV criteria and made by the first author (P.O), an experienced child psychiatrist using K-SADS-PL semi-structured interview.

Child behavior checklist (CBCL). The CBCL includes 20 competence items and 118 problem items (Achenbach 1991a). The test-retest reliability of the Turkish form was 0.84 for the Total Problems and the internal consistency was adequate $($ Cronbach alpha $=0.88)$ (Erol et al. 1995).

Teacher report form (TRF). The TRF includes 118 items for rating specific behavioral/emotional problems and 2 open-ended items like those on the CBCL (Achen- bach 1991b). The test-retest reliability of the Turkish form was .88 for the Total Problems and the internal consistency was adequate (Cronbach alpha $=0.87)($ Erol and Simsek 2000).

Conners parent rating scale (CPRS). This form includes 48 items, which aims to evaluate behavior of children assessed by their parents (Conners 1997). The scale includes oppositional behavior, inattentiveness, hyperactivity, psychosomatic and irritability domains. Turkish version has good validity and reliability (Dereboy et al. 1998).

Conners teacher rating form (CTRS). This form includes 28 items, which aim to rate classroom behavior of children assessed by teachers (Goyette et al. 1978). There are three subscales of the form: 8 items for inattentiveness, 7 items for hyperactivity and 8 items for conduct problems. CTRS is translated to Turkish by Sener et al. (1995), and the Turkish form showed adequate validity and reliability (Cronbach's alpha 0.95).

Psychiatric diagnoses including ADHD and comorbid conditions were made by K-SADS-PL. The severity of ADHD symptoms was determined by Conners Parent and Teacher Rating Scales. In addition, CBCL and TRF were used for evaluating additional emotional and behavioral problems.

\section{RLS Diagnosis}

A detailed neurological examination was conducted by an experienced specialist (EBD). We used the clinical diagnosis criteria for RLS reviewed in 2003 ([Allen et al. 2003] International Restless Legs Study Group). The criteria for definite RLS include an urge to move legs accompanied or caused by uncomfortable and unpleasant sensations in the legs; the urge to move begins or worsens during periods of rest or inactivity; the urge to move is partially or totally relieved by movement; and the urge is worse (or only occurs) in the evening or night. In children, sleep disturbance for age, definite RLS diagnosis in the relatives, and the presence of polysomnographically documented periodic limb movements during sleep are supportive criteria for RLS diagnosis.

\section{Laboratory measurements}

Laboratory values were measured using standard measurement assays. Iron deficiency was defined as ferritin level $<12 \mathrm{ng} / \mathrm{ml}$. We used the serum ferritin level of $12 \mathrm{ng} / \mathrm{ml}$ since this was used as a criterion previ- 
ously in screening studies with large samples (Halterman et al. 2001; Lozoff et al. 2003). All patients with iron deficiency were referred to pediatricians for further investigation.

\section{Data analysis}

We compared mean CTRS, CPRS, CBCL, and TRF scores and iron level, total iron binding capacity, transferrin saturation and hemoglobin values of ADHD subjects with or without RLS with analysis of variance. We used Fisher's Exact test to compare the rate of comorbidity and iron deficiency (ferritin $<12 \mathrm{ng} / \mathrm{ml}$ ). Two-tailed significance tests $(p<0.05)$ are reported throughout. SPSS 13.0 statistical package was used for the analysis.

\section{Results}

\section{Behavioral measures}

Eighty of the ADHD subjects met the criteria for combined and 7 for inattentive subtypes of ADHD. Thirty-four subjects had various comorbid conditions (which might be more than one in a single subject): 8 subjects had comorbid oppositional defiant or conduct disorders, 10 subjects had anxiety disorder, 1 subject had depression, 9 subjects had elimination disorders, 3 had speech disorders, and 16 had learning disability. None of the subjects had mental retardation (described as Wechsler Intelligence Scale for Children, Revised, Full IQ score < 70).

There were no significant difference between girls and boys in terms of behavioral or hematological measures or the rates of comorbidity $(\mathrm{F}=$ $0.004-1.33 ; p>0.26$ and $\mathrm{x}^{2}=0.009 ; p=0.97$, respectively).

\section{Rates of $R L S$}

We diagnosed RLS in subjects who fulfilled all four of the essential diagnostic criteria and who also defined the restlessness in their own words. 29 ( 27 boys, 2 girls) of 87 ADHD subjects (33.3\%) had definite RLS diagnosis. Prevalence of RLS was not different between girls and boys with ADHD ( $25 \%$ vs $34.2 \%$, respectively, $x^{2}=$ $0.28, p=0.71)$.
Comparison of ADHD Subjects with or without $R L S$

Behavioral and Hematological variables. CPRS and CTRS total scores; CBCL and TRF Internalization, Externalization and Total Problems scores were not significantly different in ADHD subjects with or without RLS (Table 1). Rate of comorbidity was not significantly different between these two groups $(36.2 \%$ vs $44.8 \%$, $\left.\mathrm{x}^{2}=1.62, p=0.45\right)$. Mean iron, hemoglobin and transferrin saturations were not significantly different in ADHD subjects with or without RLS (Table 1). There was a statistical trend of higher total iron binding capacity in the ADHD subjects with RLS $(\mathrm{F}=2.92, p=0.091)$.

Rates of iron deficiency. Six ADHD subjects with RLS $(20.7 \%)$ had serum ferritin lower than $12 \mathrm{ng} / \mathrm{ml}$. All of these subjects were male. Only one ADHD subject without RLS (1.7\%) fulfilled this condition. Thus, iron deficiency was significantly more common in ADHD subjects with RLS $\left(x^{2}=9.39, p=0.005\right.$, Fisher's Exact Test [Table 2]).

\section{Discussion}

The relationship between iron deficiency and the presence of RLS in subjects with ADHD has not been evaluated extensively. This is interesting since the previous studies (Chervin et al. 2002; Walters et al. 2004) suggested an increased risk of having another of these disorders when one of them is present. Our findings showed that RLS was quite frequent in subjects with ADHD (almost $34 \%$ ) when compared with the prevalence rates obtained from epidemiological studies, which reported the prevalence of RLS as almost $11 \%$ (Berger et al. 2004; Hogl et al. 2005). Although we did not have a control group, consistent with previous studies (Cortese et al. 2005), our results suggest that RLS is more common in subjects with ADHD than in normal population. ADHD subjects with or without RLS did not differ in behavioral problems or presence of comorbidity, age or gender. This is interesting in the light of previous studies that reported higher prevalence of RLS in females (e.g. Hogl et al. 2005). Lack of significant gender difference in our study may 
TABLE 1. Comparison of behavioral and hematological variables and comorbidity rates of ADHD subjects with or without RLS.

\begin{tabular}{|c|c|c|c|c|}
\hline & $\begin{array}{c}\mathrm{ADHD}+\mathrm{RLS} \\
(n=29)\end{array}$ & $\begin{array}{l}\mathrm{ADHD}-\mathrm{RLS} \\
\quad(n=58)\end{array}$ & $F, x^{2}$ & $p$ \\
\hline Age & $9.8 \pm 2.5$ & $9.1 \pm 2.5$ & 1.543 & .218 \\
\hline CTRS total score & $31.7 \pm 8.1$ & $33.0 \pm 11.2$ & .243 & .624 \\
\hline CPRS total score & $36.4 \pm 13.3$ & $36.8 \pm 14.4$ & .016 & .899 \\
\hline CBCL total problems & $70.9 \pm 19.7$ & $67.0 \pm 28.8$ & .343 & .560 \\
\hline CBCL externalization & $20.8 \pm 9.3$ & $21.3 \pm 11.2$ & .032 & .859 \\
\hline CBCL internalization & $16.3 \pm 6.2$ & $14.6 \pm 7.7$ & .859 & .357 \\
\hline TRF total problems & $70.8 \pm 19.7$ & $67.0 \pm 28.8$ & .343 & .560 \\
\hline TRF externalization & $20.8 \pm 9.3$ & $21.3 \pm 11.2$ & .032 & .859 \\
\hline TRF internalization & $16.3 \pm 6.2$ & $14.6 \pm 7.7$ & .859 & .357 \\
\hline Comorbidity & $44.8 \%$ & $36.25 \%$ & .603 & .489 \\
\hline Iron $(\mu \mathrm{mol} / \mathrm{l})$ & $78.2 \pm 33.1$ & $76.8 \pm 31.2$ & .037 & .849 \\
\hline Total iron binding capacity $(\mu \mathrm{mol} / \mathrm{l})$ & $367.64 \pm 47.3$ & $341.7 \pm 73.3$ & 2.91 & .091 \\
\hline Transferrin saturation (\%) & $21.8 \pm 0.9$ & $25.4 \pm 1.6$ & 1.16 & .284 \\
\hline Hemoglobin (g/dl) & $13.8 \pm .95$ & $13.8 \pm .91$ & .018 & .892 \\
\hline
\end{tabular}

CBCL, child behavior checklist; TRF, teacher report form; CPRS, conners parent rating scale; CTRS, conners teacher rating form. Comorbidity was evaluated with KSADS-PL. $n$, number of patients; $F, \mathrm{~F}$ value; $x^{2}$, Pearson chi-square value; $p$, significance level.

TABLE 2. Prevalence of iron deficiency in ADHD subjects with or without RLS.

\begin{tabular}{ccccc}
\hline & $\begin{array}{c}\text { ADHD + RLS } \\
(n=29)\end{array}$ & $\begin{array}{c}\text { ADHD - RLS } \\
(n=58)\end{array}$ & $x^{2}$ & $p$ \\
\hline Iron deficiency (ferritin $<12 \mathrm{ng} / \mathrm{ml})$ & $6(20.7 \%)$ & $1(1.7 \%)$ & 9.39 & 0.005
\end{tabular}

$n$, number of patients; $\%$, percentage of iron deficiency; $x^{2}$, Pearson chi-square value; $p$, significance level.

be due to very small number of the female subjects. Less than $10 \%$ of the subjects included in the study were female. We included all eligible subjects to the study regardless of their gender; therefore the figures reflect our clinical practice. We believe that the referral rate for girls may be lower than boys for ADHD in Turkey.

It has also been reported that iron levels might be associated with more severe behavioral problems in children with ADHD (Konofal et al. 2004). In the present study, we did not find any significant difference between the parent and teacher rating scores in patients with or without RLS, in spite of higher prevalence of iron deficiency in the former group. This might be due to low prevalence of iron deficiency in the study group. A more recent study with a small sample reported that ADHD severity was higher, although not statistically significant, in ADHD patients with RLS $(n=12)$ when compared with ADHD subjects without RLS $(n=10)$ (Konofal et al. 2007). The discrepancy between the results of the two studies might be related to differences in patient populations. Sample size of the study of Konofal et al is rather small and includes younger patients (mean 7.3 years of age) than our study. Nevertheless, the relationship between symptom severity and the presence of RLS in ADHD patients must be further evaluated in future studies. 
Konofal et al. (2007) reported that there was a statistical trend towards lower serum ferritin levels in ADHD subjects with RLS when compared with ADHD subjects without RLS. Congruent with these results, we showed that iron deficiency was more prevalent in ADHD subjects with RLS. Thus, depleted iron stores might increase the risk of having RLS in ADHD subjects. It has been well known that iron deficiency is one of the leading causes of symptomatic RLS (Allen 2004). It has been suggested that iron is closely related to dopamine metabolism being a coenzyme of tyrosine hydroxylase, and that D2 and D4 receptor and dopamine transporter densities decrease with decreased brain iron levels (Ashkenazi et al. 1982; Ericson et al. 1997). In patients with RLS, reduced brain iron concentration may be due to dysfunctional iron transportation (Mizuno et al. 2005). It can be speculated that iron deficiency may cause further alterations in brain dopaminergic system, which seems to be already impaired in ADHD subjects (Volkow et al. 2007), and lead to a higher rate of RLS, which is associated with alterations of both the iron metabolism and the dopaminergic system (Winkelman 2006). Future studies directly evaluating the dopaminergic system in iron deficiency, RLS and ADHD are necessary to gain a better understanding of these conditions.

\section{Study limitations}

There are some limitations of the present study. First, the sample size might be small when the low rate of iron deficiency is taken into account. Thus, our results must be interpreted with caution. Second, since this was a crosssectional study, it was impossible to detect causability among the factors. Third, since the female/male ratio was almost 1 to 9 , our results may not be valid for all ADHD subjects. Fourth, although it is not imperative for the diagnosis of RLS when the other criteria are fulfilled, the presence of polysomnographically documented periodic limb movements during sleep is supportive of diagnosis. Therefore, lack of polysomnographical evidence in our patients may be considered as a limitation. Last, although the rate of RLS in ADHD subjects was considerably higher than the prevalence rates obtained from the literature, this must be re-evaluated in future studies, since our sample may not be representative of all ADHD subjects and we did not have a healthy control group. Nevertheless, our results suggested that iron deficiency might be more common in subjects with ADHD and RLS. Therefore, iron deficiency must be sought in these patients.

\section{References}

Achenbach, T.M. (1991a) Manual for the Child Behavior Checklist and 1991 Profile. University of Vermont, Deparment of Psychiatry, Burlington, VT.

Achenbach, T.M. (1991b) Manual for the Teacher's Report Form and 1991 Profile. University of Vermont, Deparment of Psychiatry, Burlington, VT.

Allen, R.P. (2004) Iron, RLS, and blood donations. Sleep Med., 5, 113-114.

Allen, R.P., Pichietti, D., Hening, W.A., Trenkwalder, C., Walters, A.S. \& Montplaisir, J. (2003) Restlesss legs syndrome: diagnostic criteria, special considerations, and epidemiology. A report from the restless legs syndrome diagnosisi and epidemiology workshop at the National Institutes of Health. Sleep Med., 4, 101-119.

American Psychiatric Association (1994) Diagnostic and Statistical Manual of Mental Disorders, $4^{\text {th }}$ ed., American Psychiatric Press, Washington, D.C.

Ashkenazi, R., Ben-Shachar, D. \& Youdim, M.B.H. (1982) Nutritional iron deficiency and dopamine binding sites in the rat brain. Pharmacol. Biochem. Behav., 17, 43-47.

Berger, K., Luedemann, J., Trenkwalder, C., John, U. \& Kessler, C. (2004) Sex and risk of restless legs syndrome in general population. Arch. Intern. Med., 164, 196-202.

Chervin, R.D., Archbold, K.H., Dillon, J.E., Panahi, P., Dahl, R.E. \& Guilleminault, C. (2002) Associations between symptoms of inattention, hyperactivity, restless legs syndrome and periodic limb movement disorder. Sleep Med. Rev., 6, 253-265.

Conners, C.K. (1997) Conners' Rating Scales- Revised. North Tonawada, NY: Multi-Health Systems Publishing.

Connor, J.R., Boyer, P.J., Menzies, S.L., Dellinger, B., Allen, R.P., Ondo, W.G. \& Earley, C.J. (2003) Neuropathological examination suggests impaired brain iron acquisition in restless legs syndrome. Neurology, 61, 304-309.

Cortese, S., Konofal, E., Lecendreux, M., Arnulf, I., Mouren, M.C., Darra, F. \& Dalla Bernardina, B. (2005) Restless legs syndrome and attention-deficit/hyperactivity disorder: a review of the literature. Sleep, 28, 1007-1013.

Dereboy, C., Senol, S. \& Sener, S. (1998) Adaptation of Conners' parent rating scale in Turkish. In: Proceedings $10^{\text {th }}$ National Congress of Psychology, Ankara, Turkey.

Erikson, K., Pinero, D.J., Connor, J.R. \& Beard, J.L. (1997) Regional brain iron, ferritin and transferrin concentrations during iron deficiency and iron repletion in developing rats. J. Nutr., 127, 2030-2038.

Erol, N., Arslan, B.L. \& Akçakın, M. (1995) The adaptation and standardization of the Child Behavior Checklist among 6-18 year-old Turkish children. In: European Approaches 
to Hyperkinetic Disorder, edited by J. Sergeant Eunethydis, Zurich, Fotoratar, pp. 97-113.

Erol, N. \& Simsek, Z. (2000) Mental health of Turkish children: Behavioral and emotional problems reported by parents, teachers, and adolescents. In: International Perspectives on Child and Adolescent Mental Health, edited by N.N. Singh, J.P. Leung \& A.N. Singh, Elsevier Science Ltd., pp. 223-247.

Gokler, B., Unal, F., Pehlivantürk, B., Kültür, Ç.E., Akdemir, D. \& Taner, Y. (2004) Okul çagi çocuklari icin duygulanim bozukluklari ve sizofreni gorusme cizelgesi simdi ve yasam boyu sekli türkce uyarlamasi'nin gecerlik ve guvenirligi. Turk. J. Child Adolesc. Ment. Hlth., 11, 109-116.

Goyette, C.H., Conners, C.K. \& Ulrich, R.F. (1978) Normative data on revised Conners' parent and teacher rating scales. $J$. Abnorm. Child Psychol., 6, 221-236.

Halterman, J.S., Kaczorowski, J.M., Aligne, C.A., Auinger, P. \& Szilagyi, P.G. (2001) Iron deficiency and cognitive achievement among school-aged children and adolescents in the United States. Pediatrics, 107, 1381-1386.

Hogl, B., Kiechl S., Willeit, J, Saletu, M., Frauscher, B., Sepi, K., Muller, J., Rungger, G., Gasperi, A., Wenning, G. \& Poewe, W. (2005) Restless legs syndrome: a community-based study of prevalence, severity and risk factors. Neurology, 64, 1920-1924.

Kaufman, J., Birmaher, B., Brent, D., Rao, U., Flynn, C., Moreci, P., Williamson, D. \& Ryan, N. (1997) Schedule for Affective Disorders and Schizophrenia for School Age Children-present and life time version (KSADS-PL): initial reliability and validity data. J. Am. Acad. Child Adolesc. Psychiatry, 36, 980-988.

Konofal, E., Lecendreux, M., Arnulf, I. \& Mouren, M.C. (2004) Iron deficiency in children with attention deficit hyperactivity disorder. Arch. Pediatr. Adolesc. Med., 158, 1113-1115.

Konofal, E., Cortese, S., Marchand, M., Mouren, M.C., Arnulf, I. \& Lecendreux, M. (2007) Impact of restless legs syndrome and iron deficiency on attention-deficit hyperactivity disorder in children. Sleep Med., doi:10.1016/j.sleep.2007. 04.022

Krieger, J. \& Schroeder, C. (2001) Iron, brain and restless legs syndrome. Sleep Med. Rev., 5, 277-286.

Kryger, M.H., Otae, K. \& Foerster, J. (2002) Low body stores of iron and restless legs syndrome: a correctable cause of insomnia in adolescents and teenagers. Sleep Med., 3, 127-132.

Lozoff, B., De Andraca, I., Castillo, M., Smith, J.B., Walter, T. \& Pino, P. (2003) Behavioral and developmental effects of preventing iron-deficiency anemia in healthy full-term infants. Pediatrics, 112, 846-854.

Manconi, M., Gvoni, V., De Vito, A., Economouo, N.T., Cenik, E., Casetta, I., Mollica, G., Ferini-Strambi, L. \& Granieri, E. (2004) Restless legs syndrome and pregnancy. Neurology, 63, 1065-1069.

Mendelson, W. (2005) Sleep Disorders. In: Comprehensive Textbook of Psychiatry, 8th ed., edited by B.J. Sadock \& V.A. Sadock, Lippincott Williams \& Wilkins, Philadelphia, PA, pp. 2002-2035.

Mizuno, S., Mihara, T., Miyaoka, T., Inagaki, T. \& Horiguchi, J. (2005) CSF iron, ferritin, and transferrin levels in restless legs syndrome. J. Sleep Res., 14, 43-47.

Nieoullon, A. (2002) Dopamine and regulation of cognition and attention. Prog. Neurobiol., 67, 53-83.

Oades, R.D., Taghzouti, K., Rivet, J.M., Simon, H. \& Le Moal, M. (1986) Locomotor activity in relation to dopamine and noradrenaline in the nucleus accumbens, septal and frontal areas: a 6-hydroxydopamine study. Neuropsychobiology, 16, 37-42.

Polydefkis, M., Allen, R.P., Hauer, P., Earley, C.J., Griffin, J.W. \& McArthur, J.C. (2000) Subclinical sensory neuropathy in late-onset restless legs syndrome. Neurology, 55, $1115-1121$

Rijsman, R.M. \& De Weerd, A.W. (1999) Secondary periodic limb movement disorder and restless legs syndrome. Sleep Med. Rev., 3, 147-158.

Russell, V., De Villiers, A., Sagvolden, T., Lamm, M. \& Taljaard, J. (1995) Altered dopaminergic function in the prefrontal cortex, nucleus accumbens and caudate-putamen of an animal model of attention-deficit hyperactivity disorder - the spontaneously hypertensive rat. Brain Res., 676, 343-351.

Sagvolden, T. (2000) Behavioral validation of the spontaneously hypertensive rat (SHR) as an animal model of attentiondeficit/hyperactivity disorder (AD/HD). Neurosci. Biobehav. Rev., 24, 31-39.

Sener, S., Dereboy, C., Dereboy, I.F. \& Sertcan, Y. (1995) Conners' Teacher Rating Scale Turkish version-I. Turk. J. Child Adoles. Ment. Hlth., 2, 131-141.

Sever, Y., Ashkenazi, A., Tyrano, S. \& Weizman, A. (1997) Iron treatment in children with attention deficit hyperactivity disorder. Neuropsychobiology, 35, 178-180.

Stefansson, H., Rye, D.B., Hicks, A., Petursson, H., Ingason, A., Thorgeirsson, T.E., Palsson, S., Sigmundsson, T., Sigurdsson, A.P., Eiriksdottir, I., Soebech, E., Bliwise, D., Beck, J.M., Rosen, A., Waddy, S., Trotti, L.M., Iranzo, A., Thambisetty, M., Hardarson, G.A., Kristjansson, K., Gudmundsson, L.J., Thorsteinsdottir, U., Kong, A., Gulcher, J.R., Gudbjartsson, D. \& Stefansson, K. (2007) A genetic risk factor for periodic limb movements in sleep. $N$. Engl. J. Med., published online (doi: 10.1056/NEJ$\mathrm{MOaO} 72743$ )

Sun, E.R., Chen, C.A., Ho, G., Earley, C.J. \& Allen, R.P. (1998) Iron and restless legs syndrome. Sleep, 21, 371-377.

Trenkwalder, C., Paulus, W. \& Walters, A.S. (2005) The restless legs syndrome. The Lancet Neurol., 4, 465-475.

Volkow, N., Wang, J., Newcorn, J., Telang, F., Solanto, M.V., Fowler, J.S., Logan, J., Ma, Y., Schulz, K., Pradhan, K., Wong, J. \& Swanson, J.M. (2007) Depressed dopamine activity in caudate and preliminary evidince of limbic involvement in adults with attention deficit hyperactivity disorder. Arch. Gen. Psychiatry, 64, 932-940.

Walters, A.S., Ondo, W.G., Dreykluft, T., Grunstein, R., Lee, D. \& Sethi, K. (2004) Ropinirole is effective in the treatment of restless legs syndrome. TREAT RLS 2: A 12-week, double-blind, randomized, parallel-group, placebocontrolled study. Movement Disord., 19, 1414-1423.

Wigglesworth, J.M. \& Baum, H. (1988) Iron dependent enzymes in the brain. In: Brain Iron: Neurochemical and Behavioral Aspects, edited by M.B.H. Yuodim, Taylor and Francis, New York, pp. 25-66.

Winkelman, J.W. (2006) Considering the causes of RLS. Eur. J. Neurol., 13, (suppl. 3), 8-14.

Winkelmann, J., Polo, O., Provini, F., Nevsimalova, S. Kemlink, D., Sonka, K., Hogl, B., Poewe, W., StiasnyKolster, K., Oertel, W., de Weerd, A., Strambi, L.F., Zucconi, M., Pramstaller, P.P., Arnulf, I., Trenkwalder, C., Klein, C., Hadjigeorgiou, G.M., Happe, S., Rye, D. \& Montagna, P. (2007a) Genetics of restless legs syndrome (RLS): State-of-the-art and future directions. Mov. Disord., published online 7 June 2007 (doi:10.1002/mds.21587).

Winkelmann, J., Schormair, B., Lichtner, P., Ripke, S., Xiong, L., 
Jalilzadeh, S., Fulda, S., Pütz, B., Eckstein, G., Hauk, S., Trenkwalder, C., Zimprich, A., Stiasny-Kolster, K., Oertel, W., Bachmann, C.G., Paulus, W., Peglau, I., Eisensehr, I., Montplaisir, J., Turecki, G., Rouleau, G., Gieger, C., Illig,

T., Wichmann, H.E., Holsboer, F., Müller-Myhsok, B. \& Meitinger, T. (2007b) Genome-wide association study of restless legs syndrome identifies common variants in three genomic regions. Nat. Genet., 39, 1000-1006. 